\title{
Calcaneus quantitative ultrasound and Body Composition in Preschool Children: Physical Activity Consideration
}

\author{
Ultrasonido Cuantitativo de Calcáneo y Composición Corporal \\ en Niños Preescolares: Consideración de Actividad Física
}

Dejan M. Madic ${ }^{1}$; Nebojsa Trajkovic ${ }^{1}$; Boris Popovic ${ }^{1}$; Danilo Radanovic ${ }^{1}$ \& Goran Sporis ${ }^{2}$

MADIC, M. D.; TRAJKOVIC, N.; POPOVIC, B.; RADANOVIC, D. \& SPORIS, G. Calcaneus quantitative ultrasound and body composition in preschool children: Physical activity consideration. Int. J. Morphol., 35(4):1249-1253, 2017.

SUMMARY: The aim of this research was to determine the difference in Calcaneus quantitative ultrasound (QUS) and body composition according to physical activity in preschool children. We recruited 296 healthy children (112 girls and 184 boys) from different kindergartens in Vojvodina, Serbia. Children were evaluated for body composition. Quantitative ultrasound (QUS) measurements of the heel were performed using the Speed of sound, Broadband Ultrasound Attenuation, Quantitative Ultrasound Index and Estimated bone mineral density for further analysis. Furthermore, children were divided into three groups according to physical activity. Apart from the differences in Body fat $\%$ and body mass, there were no significant group differences for BMI, waist circumference and abdominal skinfold ( $\mathrm{p}>0.05$ ). The ANOVA showed significant differences $(\mathrm{p}<0.05)$ in all QUS measurements between three different intensities of physical activity. The results show that Body Mass and Body fat $\%$ were important predictors that discriminate children according to physical activity. Moreover, the results show that beside BMI and Body fat \%, all calcaneus QUS measurements showed differences according to physical activity. In conclusion, our study showed differenses in all calcaneus QUS measurements according to physical activity level.

KEY WORDS: Bone health; Body weight; Children; Difference.

\section{INTRODUCTION}

Physical activity (PA) is very important for children for healthy living, and inactivity has been identified as a significant predictor for overweight and obesity during childhood (Cantell et al., 2012). Research on PA in preschoolaged is children difficult due to the fact that there are no evidence-based guidelines (Katzmarzyk \& Ardern, 2004). There are also contradictory statements concerning the amount of PA in preschool children. The National Association for Sport and Physical Education (NASPE) has released PA guidelines for young children that recommend at least $120 \mathrm{~min}$ of PA per day, with half the time spent in structured settings and the other half in unstructured settings (Cantell et al.). However, aforementioned authors found other recommendations with at least 60 min of moderateto-vigorous intensity PA daily.

Moderate to high intensive physical activity, including jumping and resistance training, can help with the bones health maintenance in mature years (Kohrt et al., 2004). Significant positive links have been reported between regular participation in sports and mineral density of bones in childhood (Slemenda et al., 1991; Schönaü et al., 1993; Ruiz et al., 1995). Recently, Harvey et al. (2012) have shown that the levels of the typical daily physical activity are positively correlated with bone density in four-year-old children. Beside the fact that physically active children have greater bone mass or density than sedentary children (Heinonen et al., 1993; Heinonen et al., 1995; Lima et al., 2001), the researchers have tried to connect aerobic activities with bone mass, but the results are inconsistent. Laabes $e t$ al. (2008) recruited male athletes from different sports and found that football is a significant determinant of speed of sound independent of age, height, weight and BMI. Troiano et al. (1995), reported that the prevalence of overweight is increasing among boys and girls of all age groups and suggested increasing physical activity as a means to address this important health problem.

Physical activity during pubertal growth stimulates both bone and skeletal muscle hypertrophy to a greater

${ }^{1}$ Faculty of Sport and Physical Education, University of Novi Sad, Serbia.

${ }^{2}$ Faculty of Kinesiology, University of Zagreb, Croatia. 
degree than observed with normal growth in non-physically active children (Vicente-Rodríguez, 2006). However, there is an increased sedentarism in children, especially in girls (Goran et al., 1999), which is an important issue concerning the association of PA and bone density. Therefore, it is of great importance to know how PA affects bone development and accordingly what type of activity is best suitable for children. Thus, the aim of this research was to determine the difference in Calcaneus QUS and body composition according to physical activity in preschool children.

\section{MATERIAL AND METHOD}

Subjects. We recruited 296 healthy children (112 girls and 184 boys) from different kindergartens in Vojvodina, Serbia. Descriptive characteristics of participants are presented in Table 1. Parents were informed about the assessment from the school physician. All individuals and their parents gave their consent to participate in the study before investigation. The inclusion criteria for participation in the study were as follows: not suffering from chronic diseases or taking medication on a regular basis, not having a history of diseases that could affect bone, and not having immobilized any part of the body during 6 months before the evaluation. Eight children did not agree to take part in the study. The study was conducted according to the guidelines laid down in the Declaration of Helsinki and all procedures involving human subjects were approved by the ethical committee of each survey centre.

Testing procedures. Medical history from all children was obtained from their school physician. Height was measured on a portable stadiometer, to the nearest $0.5 \mathrm{~cm}$. Body composition was determined by a body-fat analyzer (BF 905 , Maltron, UK). Body mass index (BMI) was calculated through the following formula: body weight $(\mathrm{kg}) \div$ height $2(\mathrm{~m})$. Weight circumferences was measured to the nearest $0.1 \mathrm{~cm}$ at the level of the iliac crest while the subject was at minimal respiration. Abdominal skinfold thickness was measured with a skinfold caliper.

For PA habits, each parent was asked how often their child participated in general PA (e.g., going for walks, playing outdoors, skating), and how often they participate in organized PA (e.g., swim class, gym class). Participating children were asked how many times per week they "played or exercised enough to make them sweat or breathe hard." These activities did not exclude school-related involvements such as physical education. We consider low PA when children could not accumulate at least $60 \mathrm{~min}$ of moderate-to-vigorous PA daily. Moderate PA involves 60 min of moderate-to-vigorous PA daily, while high PA includes recommendation in which children must be engage in at least 120 min of PA per day, with half the time spent in structured settings and the other half in unstructured settings.

Bone density. Quantitative ultrasound (QUS) measurements of the heel were performed using "Sahara" sonometer ("Hologic," Bedford, MA). We used the calcaneus bone for QUS assessment because it contains a large percentage of trabecular bone, which has a high metabolic turnover rate (Töyräs et al., 2002). The primary parameters measured with ultrasound were BUA and speed of sound (SOS). BUA (dB/ $\mathrm{MHz}$ ) is the attenuation of sound waves as they pass from the transmitting transducer to the receiving transducer. SOS (m/ $\mathrm{sec}$ ) is the speed the ultrasound signal travels from one transducer to the other. Normal bone has a higher attenuation (BUA) and speed of sound (SOS) than osteoporotic bone. These two parameters can be combined to form a new parameter, the quantitative ultrasound index (QUI) referred as ultrasound stiffness. QUI was calculated automatically using the equation "QUI $=0.41 \times($ BUA + SOS $)-571$," without a unit of measurement (Frost et al., 2000; Kwok et al., 2012). The Est. BMD $(\mathrm{g} / \mathrm{cm} 2)$ was calculated using the following equation "EBMD $=0.002592 \times($ BUA+ SOS $)-3.687 "$ (Frost et al.$)$. All measurements were performed by the same investigator throughout the study. The EBMD was not a direct measurement of the heel BMD. However, EBMD has proven to be a useful parameter for the assessment of calcaneal BMD in previous studies (Frost et al.). To examine short-term precision in vivo, 10 children had two repositioned measurements. The coefficient of variation percent (CV\%) was 3.1, 1.6, 3.6 and $4.4 \%$ for BUA, SOS, QUI and estimated BMD, respectively.

Statistical analysis. Data analysis was performed using the Statistical Package for the Social Sciences (v13.0, SPSS Inc., Chicago, IL, USA). Statistical significance was set at $\mathrm{p}<0.05$. The mean and standard deviations were calculated for the subject characteristics, body composition and QUS measurements. The subject characteristics of the groups were compared with one-way analysis of variance (ANOVA). When the ANOVA indicated a significant difference $(\mathrm{p}<0.05)$, Tukey's range method was used as the post-hoc test.

\section{RESULTS}

Descriptive statistics for the different physical activities of participants are shown in Table I. Apart from the expected differences in Body fat $\%$ and body mass, there were no significant group differences for BMI, waist circumference and abdominal skinfold ( $p>0.05)$. Moreover, children with low PA were significantly taller than high vigorous, as well as moderate PA children. 
Table I. Body composition in three different levels of PA.

\begin{tabular}{lcccc}
\hline & Moderate PA & High PA & Low PA & \multirow{2}{*}{$\mathrm{p}$} \\
\cline { 2 - 4 } & $(\mathrm{n}=137)$ & $(\mathrm{n}=112)$ & $(\mathrm{n}=47)$ & \\
\hline Height & $115.26 \pm 7.76^{* *}$ & $120.34 \pm 8.54^{*}$ & $125.92 \pm 9.34^{*}$ & $0.001 \dagger$ \\
Weight & $21.50 \pm 4.49^{* *}$ & $23.85 \pm 5.16^{*}$ & $26.78 \pm 6.22^{*}$ & $0.001 \dagger$ \\
BMI & $16.02 \pm 1.75$ & $16.30 \pm 1.88$ & $16.71 \pm 2.37$ & 0.108 \\
BFAT & $19.02 \pm 3.07^{* *}$ & $18.92 \pm 3.73$ & $20.03 \pm 3.38^{*}$ & $0.033 \dagger$ \\
Waist circumference & $56.57 \pm 6.42$ & $56.84 \pm 5.75$ & $57.34 \pm 7.31$ & 0.70 \\
Abdominal skinfold & $6.82 \pm 3.37$ & $6.93 \pm 3.88$ & $7.44 \pm 3.97$ & 0.40 \\
\hline
\end{tabular}

$\dagger$ Significant difference between groups $(\mathrm{p}<0.05)$; *Significantly different from low PA; **Significantly different from low PA;

Table II. QUS measurement in three different levels of PA.

\begin{tabular}{lcccc}
\hline & Moderate PA & High PA & Low PA & \multirow{2}{*}{$\mathrm{p}$} \\
\cline { 2 - 4 } & $(\mathrm{n}=116)$ & $(\mathrm{n}=103)$ & $(\mathrm{n}=47)$ & \\
\hline EBMD & $0.54 \pm .094^{*}$ & $0.52 \pm .073$ & $0.49 \pm .071$ & $.007 \dagger$ \\
QUI & $97.63 \pm 14.89^{*}$ & $94.56 \pm 12.08$ & $89.92 \pm 11.75$ & $.004 \dagger$ \\
BUA & $59.37 \pm 18.41^{*}$ & $57.73 \pm 15.33$ & $52.24 \pm 12.74$ & $.044 \dagger$ \\
SOS & $1571.27 \pm 23.35^{*}$ & $1566.15 \pm 17.72$ & $1560.58 \pm 21.71$ & $.012 \dagger$ \\
\hline
\end{tabular}

$\dagger$ Significant difference between groups $(\mathrm{p}<0.05)$; *Significantly different from low PA; SOSSpeed of sound; BUA- Broadband Ultrasound Attenuation; QUI- Quantitative Ultrasound Index; EBMD- estimated bone mineral density.

Group comparisons with respect to the Calcaneus QUS measurement and according to physical activity are shown in Table II. The ANOVA showed significant differences $(\mathrm{p}<0.05)$ between three different intensities of PA. Post hoc test revealed significant differences between vigorous and low PA in all measured variables.

\section{DISCUSSION}

Bone health in children recently became very important medical care that leads to an increased interest in bones densitometry. Accordingly, the present study involved a population of healthy preschool children and provides novel data about bone density as indicated by QUS measurements. The results show that Body Mass and Body fat\% were important predictors that discriminate children according to physical activity. Moreover, the results show that beside BMI and Body fat\%, all calcaneus QUS measurements showed differences according to physical activity level.
Regarding body composition, in the present study we found that calcaneus QUS variables were significantly different according to physical activity. Children with low PA are significantly heavier than other groups, with higher body fat \%. Interestingly, there were no differences in BMI between groups. Data from the previous studies suggest that high levels of PA in children and young adults could be an effective preventive strategy to reduce the risk of osteoporosis in later life.

Cvijetic et al. (2003) and Rauch et al. (2004) and more recently Gracia-Marco et al. (2012) using the linear regression found that only Lean Mass contributed significantly to the variance in BUA values. The aforementioned authors explain these results with mechanostat theory, which predicts that the increase in muscle mass during development creates the stimulus for the increase in bone mass.

Calcaneus QUS measurement is important research tool for detecting low bone mass in pediatric population (Specker \& Schoenau, 2005). The results from our study 
concerning a bone benefit with physical activity is consistent with cross-sectional studies showing that physically active children have greater bone mass or density than sedentary children (Slemenda et al.; Boot et al., 1997; Jones \& Dwyer, 1998). Janz et al. (2008), studying a sample which included 449 children, with an average age of 11 , and using a questionnaire for the self-evaluation of the physical activities of children, noted a correlation between body height, body weight and maturity and bone mineral content. Additionally, longitudinal studies show that high childhood activity is associated with high adult bone density (Välimäki et al., 1994; Welten et al., 1994).

Our study showed differences in all calcaneus QUS measurements according to physical activity level. There is a need for further longitudinal research to find the best time during the growth period when loading is most effective. Physical activity and calcium intake are considered the major environmental factors influencing bone mass. However, limitation of our study could be the fact that measured physical activities, such as the intensity and duration of recreation and sport activities, were not analyzed objectively. Additionally, dietary calcium intakes were not considered for analysis in this research.

MADIC, D.; TRAJKOVIC, N.; POPOVIC, B.; RADANOVIC, D. \& SPORIS, G. Ultrasonido cuantitativo de calcáneo y composición corporal en niños preescolares: Consideración de actividad física. Int. J. Morphol., 35(4):1249-1253, 2017.

RESUMEN: El objetivo de esta investigación fue determinar la diferencia entre el ultrasonido cuantitativo (USC) de calcáneo y la composición corporal según la actividad física en niños en edad preescolar. Se estudiaron 296 niños sanos (112 niñas y 184 niños) de diferentes jardines infantiles en Vojvodina, Serbia. Se evaluó la composición corporal de los niños. Las medidas de USC del talón se realizaron utilizando la velocidad del sonido, atenuación de ultrasonido de banda ancha, el índice de ultrasonidos cuantitativos y la densidad mineral ósea estimada para un análisis posterior. Los niños se dividieron en tres grupos según actividad física. Además de las diferencias de porcentaje de grasa corporal y masa corporal, no se observaron diferencias significativas de grupo en el índice de masa corporal (IMC), circunferencia de cintura y el pliegue abdominal ( $p>0,05)$. El test de ANOVA mostró diferencias significativas $(\mathrm{p}<0,05)$ en todas las mediciones USC entre tres diferentes intensidades de actividad física. Los resultados muestran que la masa corporal y la grasa corporal fueron indicadores importantes que permiten diferenciar a los niños según la actividad física. Por otra parte, los resultados muestran que además del IMC y el porcentaje de grasa corporal, todas las mediciones de USC del calcáneo mostraron diferencias según el nivel de actividad física. En conclusion, nuestro estudio mostró diferencias en el USC de acuerdo al nivel de actividad física.

PALABRAS CLAVE: Salud osea; Peso corporal; Niños; Diferencia.

\section{REFERENCES}

Boot, A. M.; de Ridder, M. A.; Pols, H. A.; Krenning, E. P. \& de Munick Keizer-Schrama, S. M. Bone mineral density in children and adolescents: relation to puberty, calcium intake, and physical activity. J. Clin. Endocrinol. Metab., 82(1):57-62, 1997.

Cantell, M.; Crawford, S. G. \& Dewey, D. Daily physical activity in young children and their parents: A descriptive study. Paediatr. Child Health., 17(3):e20-4, 2012.

Cvijetic, S.; Baric, I. C.; Bolanca, S.; Juresa, V. \& Ozegovic, D. D. Ultrasound bone measurement in children and adolescents. Correlation with nutrition, puberty, anthropometry, and physical activity. J. Clin. Epidemiol., 56(6):591-7, 2003.

Frost, M. L.; Blake, G. M. \& Fogelman, I. Can the WHO criteria for diagnosing osteoporosis be applied to calcaneal quantitative ultrasound? Osteoporos. Int., 11(4):321-30, 2000.

Goran, M. I.; Reynolds, K. D. \& Lindquist, C. H. Role of physical activity in the prevention of obesity in children. Int. J. Obes. Relat. Metab. Disord., 23 Suppl., 3:S18-33, 1999.

Gracia-Marco, L.; Ortega, F. B.; Jiménez-Pavón, D.; Rodríguez, G.; Castillo, M. J.; Vicente-Rodríguez, G. \& Moreno, L. A. Adiposity and bone health in Spanish adolescents. The HELENA study. Osteoporos. Int., 23(3):93747, 2012.

Harvey, N. C.; Cole, Z. A.; Crozier, S. R.; Kim, M.; Ntani, G.; Goodfellow, L.; Robinson, S. M.; Inskip, H. M.; Godfrey, K. M.; Dennison, E. M.; Wareham, N.; Ekelund, U.; Cooper, C. \& SWS Study Group. Physical activity, calcium intake and childhood bone mineral: a population-based cross-sectional study. Osteoporos. Int., 23(1):121-30, 2012.

Heinonen, A.; Oja, P.; Kannus, P.; Sievänen, H.; Haapasalo, H.; Mänttäri, A. \& Vuori, I. Bone mineral density in female athletes representing sports with different loading characteristics of the skeleton. Bone, 17(3):197203, 1995.

Heinonen, A.; Oja, P.; Kannus, P.; Sievänen, H.; Mänttäri, A. \& Vuori, I. Bone mineral density of female athletes in different sports. Bone Miner., 23(1):14, 1993.

Janz, K. F.; Lutuchy, E. M.; Wenthe, P. \& Levy, S. M. Measuring activity in children and adolescents using self-report: PAQ-C and PAQ-A. Med. Sci. Sports Exerc., 40(4):767-72, 2008.

Jones, G. \& Dwyer, T. Bone mass in prepubertal children: gender differences and the role of physical activity and sunlight exposure. J. Clin. Endocrinol. Metabol., 83(12):4274-9, 1998.

Katzmarzyk, P. T. \& Ardern, C. J. Physical activity levels of Canadian children and youth: Current issues and recommendations. Can. J. Diabetes, 28:6778, 2004.

Kohrt, W. M.; Bloomfield, S. A.; Little, K. D.; Nelson, M. E.; Yingling, V. R. \& American College of Sports Medicine. American College of Sports Medicine Position Stand: physical activity and bone health. Med. Sci. Sports Exerc., 36(11):1985-96, 2004.

Kwok, T.; Khoo, C. C.; Leung, J.; Kwok, A.; Qin, L.; Woo, J. \& Leung, P. C. Predictive values of calcaneal quantitative ultrasound and dual energy $\mathrm{X}$ ray absorptiometry for non-vertebral fracture in older men: results from the MrOS study (Hong Kong). Osteoporos. Int., 23(3):1001-6, 2012.

Laabes, E. P.; Vanderjagt, D. J.; Obadofin, M. O.; Sendeht, A. J. \& Glew, R. $\mathrm{H}$. Assessment of the bone quality of black male athletes using calcaneal ultrasound: a cross-sectional study. Nutr. Metab. (Lond.), 5:13, 2008.

Lima, F.; De Falco, V.; Baima, J.; Carazzato, J. G. \& Pereira, R. M. Effect of impact load and active load on bone metabolism and body composition of adolescent athletes. Med. Sci. Sports Exerc., 33(8):1318-23, 2001.

Rauch, F.; Bailey, D. A.; Baxter-Jones, A.; Mirwald, R. \& Faulkner, R. The 'muscle-bone unit' during the pubertal growth spurt. Bone, 34(5):771-5, 2004.

Ruiz, J. C.; Mandel, C. \& Garabedian, M. Influence of spontaneous calcium intake and physical exercise on the vertebral and femoral bone mineral density of children and adolescents. J. Bone Miner. Res., 10(5):675-82, 1995. 
MADIC, D.; TRAJKOVIC, N.; POPOVIC, B.; RADANOVIC, D. \& SPORIS, G. Calcaneus quantitative ultrasound and body composition in preschool children: Physical activity consideration. Int. J. Morphol., 35(4):1249-1253, 2017.

Schönaü, E.; Wentzlik, U.; Michalk, D.; Scheidhauser, K. \& Klein, K. Is there an increase of bone density in children? Lancet, 342(8872):689-90, 1993.

Slemenda, C. W.; Miller, J. Z.; Hui, S. L.; Reister, T. K. \& Johnston, C. C. Jr. Role of physical activity in the development of skeletal mass in children. J. BoneMiner. Res., 6(11):1227-33, 1991.

Specker, B. L. \& Schoenau, E. Quantitative bone analysis in children: curren methods and recommendations. J. Pediatr., 146(6):726-31, 2005.

Töyräs, J.; Nieminen, M. T.; Kröger, H. \& Jurvelin, J. S. Bone mineral density, ultrasound velocity, and broadband attenuation predict mechanical properties of trabecular bone differently. Bone, 31(4):503-7, 2002.

Troiano, R. P.; Flegal, K. M.; Kuczmarski, R. J.; Campbell, S. M. \& Johnson, C. L. Overweight prevalence and trends for children and adolescents. The National Health and Nutrition Examination Surveys, 1963 to 1991. Arch. Pediatr. Adolesc. Med., 149(10):1085-91, 1995.

Välimäki, M. J.; Kärkkäinen M.; Lamberg-Allardt, C.; Laitinen, K.; Alhava, E.; Heikkinen J.; Impivaara, O.; Mäkelä, P.; Palmgren, J.; Seppänen, R. \& Vuori, I. Exercise, smoking, and calcium intake during adolescence and early adulthood as determinants of peak bone mass. Cardiovascular Risk in Young Finns Study Group. B. M. J., 309(6949):230-5, 1994

Vicente-Rodríguez, G. How does exercise affect bone development during growth? Sports Med., 36(7):561-9, 2006.

Welten, D. C.; Kemper, H. C.; Post, G. B.; Van Mechelen, W.; Twisk, J.; Lips, P. \& Teule, G. J. Weight-bearing activity during youth is a more important factor for peak bone mass than calcium intake. J. Bone Miner. Res., 9(7):1089-96, 1994.

\author{
Corresponding author: \\ Nebojsa Trajkovic \\ Faculty of Sport and Physical Education \\ University of Novi Sad \\ SERBIA
}

E-mail:nele_trajce@yahoo.com

Received: 24-05-2017

Accepted: 14-07-2017 